\title{
Modelo de atenção à saúde indígena: o caso do DSEI Xingu
}

\author{
Indigenous health care model: the case of the \\ DSEl Xingu
}
Modelo de atención a la salud indígena: el caso del DSEI Xingu

\author{
Sofia Beatriz Machado de Mendonça 1,2 \\ Douglas Rodrigues 1 \\ Pedro Paulo Gomes Pereira 1
}

doi: 10.1590/0102-311X00008119

O modelo de atenção à saúde indígena desenvolvido no país, expresso na proposta da Política Nacional de Atenção à Saúde dos Povos Indígenas (PNASPI), publicada em 2002, e organizado em um Subsistema de Atenção à Saúde Indígena (SasiSUS) 1, parte dos mesmos princípios e diretrizes do Sistema Único de Saúde (SUS) e reflete as orientações da Declaração de Alma-Ata sobre a atenção primária 2,3. O objetivo deste texto é refletir sobre o modelo de atenção à saúde, implantado no Distrito Sanitário Especial Indígena do Xingu (DSEI Xingu), considerando o contexto sociopolítico atual e as especificidades regionais.

O Projeto Xingu, programa de extensão universitária da Escola Paulista de Medicina (EPM), da Universidade Federal de São Paulo (Unifesp), atua entre os povos do Parque Indígena do Xingu desde 1965, contemplando atividades de atenção, ensino e pesquisa. Acompanhamos a construção de um sistema local de saúde no Xingu desde a década de 1980. Desenhamos, junto com lideranças indígenas, homens, mulheres e agentes de saúde, um modelo de atenção à saúde que pudesse dialogar com as práticas tradicionais, considerando todos os atores que produzem saúde e lidam com o adoecimento. Desde o início da formação dos agentes indígenas de saúde (AIS), na década de 1980, em suas diferentes turmas, e durante a formação dos auxiliares de enfermagem indígenas (AEI), envolvendo as equipes locais de saúde, a aproximação e a cumplicidade entre a equipe, os profissionais indígenas e os usuários possibilitaram um diálogo profícuo, abrindo espaço para escuta, não só nos contextos da atenção individual, mas, principalmente, no acesso a outros saberes e práticas de saúde, outras formas de interpretar o processo saúde/doença 4 . Buscamos implicar os atores que produziam saúde no território, em uma construção coletiva de um modelo de atenção pautado pela vigilância em saúde 5 , em que o processo de trabalho compartilhava o conceito de "trabalho vivo" proposto por Merhy e Franco 6,7. Ao longo do processo de formação eram compartilhados informações e indicadores de saúde, entre eles, o coeficiente de mortalidade infantil. Apesar das grandes oscilações apresentadas pelos indicadores de saúde, no contexto de pequenas populações, foi possível acompanhar a tendência de queda, analisando a série histórica 8,9. Muitos indígenas, particularmente os mais velhos, que viveram a era das epidemias, associavam a entrada das vacinas à diminuição da mortalidade infantil no Parque. Nessa ocasião, o modelo sanitarista campanhista predominava e conseguia dar resposta às necessidades mais prementes de saúde entre os povos xinguanos. Durante a década de 1990, tivemos o curso de
${ }^{1}$ Universidade Federal de São Paulo, São Paulo, Brasil.

${ }^{2}$ Associação Paulista para

o Desenvolvimento da

Medicina, São Paulo, Brasil.

Correspondência

S. B. M. Mendonça

Universidade Federal de

São Paulo.

Av. Nhandu 1428, São Paulo, SP 04059-004, Brasil.

sofia.xingu@gmail.com 
formação dos AIS, momento em que a troca de saberes, o compartilhar cuidados e práticas, e a implantação de um sistema local de saúde no Xingu foram determinantes para a melhoria dos indicadores de saúde. Os alunos dos cursos de AIS e AEI associavam as ações preventivas, educação em saúde e a sua participação no diagnóstico precoce, particularmente das doenças respiratórias e diarreicas, à diminuição do número de mortes entre as crianças. Outra intervenção de impacto na mortalidade infantil foi a instalação dos sistemas de abastecimento de água nas aldeias, diminuindo o número de casos de diarreia entre as crianças, particularmente, nas estações chuvosas. Durante o período de 1999 e 2004, o Projeto Xingu, em convênio com o Ministério da Saúde, apoiou a implementação do DSEI Xingu. O modelo de atenção, que passou a se configurar, era basicamente pautado pela vigilância da saúde 5 . Ao longo do tempo, novos cursos de formação aconteceram, entre 2005 e 2012, e o contexto da saúde no Xingu colocou outras necessidades de saúde que demandavam mudanças no processo de trabalho.

Em 2010, com a criação da Secretaria Especial de Saúde Indígena (SESAI), a organização do processo de trabalho nos distritos sanitários mudou. Houve um grande investimento na contratação de profissionais de saúde para o trabalho em área e, em seguida, a partir de 2013, o Programa Mais Médicos do Brasil levou 339 médicos para dentro das áreas indígenas 10,11, o que sempre foi um desafio para a atenção à saúde nestes territórios. Em muitos lugares, esse investimento trouxe bons resultados e, concretamente, aumentou o acesso aos serviços de saúde. Por outro lado, essa mudança no processo de trabalho trouxe uma série de questões que precisam ser analisadas em suas práticas e seu impacto na saúde das comunidades. No DSEI Xingu houve uma ruptura do modelo da vigilância em saúde e a reinstalação de um modelo assistencial biomédico. A equipe que antes funcionava de maneira horizontal, capilarizada, com a utilização de protocolos e corresponsabilização, passou a ter como foco o atendimento médico e suas prescrições. Os AIS têm sido excluídos do planejamento, da tomada de decisões, relegados ao cargo de acompanhantes, tradutores ou distribuidores de remédios nas aldeias. Embora tenha ocorrido um grande aumento dos profissionais de campo, seu despreparo para o trabalho em área, a oferta irregular de insumos, medicamentos, equipamentos e o pouco investimento em infraestrutura, tecnologia adequada e na formação das pessoas, somados ao modelo médico centrado, contribuíram para a diminuição da resolutividade dos serviços de saúde em área 10. Temos observado uma tendência à reversão de indicadores de saúde, como o aumento da mortalidade infantil, particularmente a partir de 201312.

O SasiSUS é uma conquista do movimento indígena, indigenista e sanitarista. Cresceu, chegou a regiões antes desassistidas, melhorou o acesso aos serviços de saúde e, em algumas regiões, impactou positivamente os indicadores de saúde. No entanto, temos constatado que a concepção inicial do Subsistema vem sendo desconstruída, assim como o paradigma da atenção diferenciada. Algumas informações provenientes de relatórios de campo da equipe do Projeto Xingu, em diferentes momentos, sinalizam uma mudança na tendência de queda da mortalidade infantil, que pode estar associada a múltiplos aspectos ${ }^{12}$. Entre estes estão fatores relacionados à falta de articulação e às fragilidades da rede de atenção regional, e fatores associados à organização dos serviços de saúde oferecidos no DSEI Xingu. Um dos principais aspectos que deve ser apontado é a implementação de um modelo médico centrado, que fragmentou o processo de trabalho, deslocando o foco da saúde para a doença, perdeu espaço de escuta e diálogo entre as equipes e as comunidades e relegou o AIS a um papel menor, burocrático e descolado da equipe. Com esses elementos, o acompanhamento das gestantes e dos recém-nascidos nas aldeias, e do parto nas cidades, ficou desconectado, perdeu-se a integralidade e a longitudinalidade da atenção.

Garantir aos povos indígenas o acesso à atenção integral à saúde, de acordo com os princípios e diretrizes do SUS, contemplando a diversidade social, cultural, geográfica, histórica e política, como propugna a PNASPI 2, passa por incorporar efetivamente o SasiSUS, capilarizar as redes de atenção à saúde às aldeias e polos-base, assumindo-os como legítima porta de entrada.

A experiência do Projeto Xingu e as pesquisas em andamento apontam que, para alcançar maior resolutividade e qualidade da atenção à saúde dos povos indígenas, é necessário implementar outras configurações do processo de trabalho, de equipamentos e tecnologias, para dar conta das especificidades, garantir vínculo e produzir saúde com a participação social 5,6,13,14,15. Muitos são os desafios, mas acreditamos que a consolidação do SasiSUS passa por uma gestão e atenção diferenciadas e pelo protagonismo indígena na condução do processo de produção da saúde em seu território. 


\section{Colaboradores}

S. B. M. Mendonça elaborou o artigo, colaborou com a sua concepção, desenho, análise e interpretação das informações e redação do artigo. D. Rodrigues colaborou na concepção e redação do artigo. P. P. G. Pereira colaborou na redação e revisão final da versão a ser publicada.

\section{Informações adicionais}

ORCID: Sofia Beatriz Machado de Mendonça (0000-0002-3801-9343); Douglas Rodrigues (00000002-6810-5410); Pedro Paulo Gomes Pereira (0000-0002-0298-2138).

\section{Referências}

1. Brasil. Lei no 9.836, de 23 de setembro de 1999. Acrescenta dispositivos à Lei no 8.080 , de 19 de setembro de 1990, que "dispõe sobre as condições para a promoção, proteção e recuperação da saúde, a organização e o funcionamento dos serviços correspondentes e dá outras providências", instituindo o Subsistema de Atenção à Saúde Indígena. Diário Oficial da União 1999; 242 set.

2. Fundação Nacional de Saúde. Política Nacional de Atenção à Saúde dos Povos Indígenas. 2a Ed. Brasília: Fundação Nacional de Saúde; 2002.

3. Declaração de Alma-Ata. Conferência Internacional sobre Cuidados Primários de Saúde. Alma-Ata: Organização Mundial da Saúde; 1978.

4. Ferreira LO. Interculturalidade e saúde indígena no contexto das políticas públicas brasileiras. In: Langdon EJ, Cardoso MD, organizadoras. Saúde indígena: políticas comparadas na América Latina. Florianópolis: Editora da UFSC; 2015. p. 217-46

5. Oliveira CM, Casanova AO. Vigilância da saúde no espaço de práticas da atenção básica. Ciênc Saúde Colet 2009; 14:929-36.

6. Campos GWS. Saúde Paidéia. São Paulo: Editora Hucitec; 2003.

7. Merhy EE, organizador. O trabalho em saúde: olhando e experienciando o SUS no cotidiano: o debate no campo da saúde coletiva. 4a Ed. São Paulo: Editora Hucitec; 2007.

8. Coimbra Jr. CEA, Santos RV, Escobar AL, organizadores. Epidemiologia e saúde dos povos indígenas no Brasil. Rio de Janeiro: Editora Fiocruz/Abrasco; 2005.

\section{Agradecimentos}

Ao Projeto Xingu, programa de extensão da Universidade Federal de São Paulo; ao Programa de Pósgraduação em Saúde Coletiva do Departamento de Medicina Preventiva da Universidade Federal de São Paulo.
9. Pagliaro H, Azevedo MM, Santos RV, organizadores. Demografia dos povos indígenas no Brasil. Rio de Janeiro: Editora Fiocruz; 2005.

10. Rodrigues D, Mendonça S. Velhas e novas ameaças no Xingu. In: Ricardo F, Ricardo B, organizadores. Povos indígenas no Brasil 2011/2016. São Paulo: Instituto Socioambiental; 2017. p. 585-90.

11. Fontão MAB, Pereira EL. Projeto Mais Médicos na saúde indígena: reflexões a partir de uma pesquisa de opinião. Interface (Botucatu) 2017; 21 Suppl 1:1169-80.

12. Setor de Informações do DSEI Xingu, Projeto Xingu - EPM/Unifesp. Número de óbitos em menores de um ano por período neonatal e pós-neonatal, DSEI Xingu 2011 a 2016. São Paulo: Universidade Federal de São Paulo; 2018.

13. Merhy EE. Em busca do tempo perdido: a micropolítica do trabalho vivo em saúde. In: Merhy EE, Onocko R, organizadores. Agir em Saúde: um desafio para o público. São Paulo: Editora Hucitec; 1997. p. 71-112.

14. Mendonça S. Saúde indígena: distâncias que aproximam. Cadernos Humaniza SUS, v. 2. Brasília: Ministério da Saúde; 2010.

15. Langdon EJ. Uma avaliação crítica da atenção diferenciada e a colaboração entre antropologia e profissionais de saúde. In: Langdon EJ, Garnelo L, organizadoras. Saúde dos povos indígenas: reflexões sobre antropologia participativa. Rio de Janeiro: Contra Capa/Associação Brasileira de Antropologia; 2004. p. 33-52.
Recebido em 15/Jan/2019

Versão final reapresentada em 24/Jun/2019

Aprovado em 26/Jun/2019 